MATEC Web of Conferences 47, 04003 (2016)

DOI: $10.1051 /$ matecconf/20164704003

(C) Owned by the authors, published by EDP Sciences. 2016

\title{
Maintenance of Heritage Building: A Case Study from Ipoh, Malaysia
}

\author{
Seong Yeow Tan ${ }^{1, a}$, Abdullateef Olanrewaju ${ }^{1}$ and Lim Tat Lee ${ }^{1}$ \\ ${ }^{1}$ Department of Construction Management, Faculty of Engineering and Green Technology, Universiti Tunku Abdul \\ Rahman, 31900 Kampar, Malaysia
}

\begin{abstract}
Heritage buildings represent the tangible cultural heritage of a community. However, many of the heritage buildings have being left neglected. Ipoh as a city rich in heritage, has many dilapidated heritage buildings which are experiencing a resurging interest. However, the problems faced by many owners are the lack of technical information of such buildings, leading to premature abandonment and demolition. Therefore, the objectives of this study are to determine the types and extent of defects present in the building studied. To achieve these objectives, a case study of a century old heritage property in Ipoh, Perak was conducted. The study aims to provide reference to owners and those responsible for the conservation of heritage buildings with similar conditions to identify and prioritize critical defects in relation to the building life span to determine its condition. The findings determined the probable causes of defects such as settlement and façade cracks, which are over 30 years old, were attributed to leaking plumbing pipes, rainwater ingress and the construction of an adjacent 20 story apartment building. The major issues to address were stabilizing the foundation through cement grouting, reinforcing the existing structural systems and roof systems as well as arresting the decay of timber floor structure. In conclusion, major maintenance guidelines are need to address structural issues and weather tightness of the building envelope, especially its roof and drainage systems.
\end{abstract}

\section{Introduction}

Cultural heritage constitutes the practices and objects passed on from previous generations. Building as an object of built heritage represents the historical evidences and values of the local community [1]. Malaysia is endowed with a number of heritage buildings in many state capitals that serve as sources of livelihood and prestige to the owners and nation. While some of the heritage buildings are declared 'national heritage', a number are owned by private individuals or associations which are yet to be registered but contribute no less to the heritage and tourism landscape [2]. These notable building typologies include the shop houses of Southeast Asia and were used for various purposes including education, residences, offices, community halls, businesses and warehouses [3]. However, many of these heritage shop-houses have being left neglected, leading to scores of dilapidations and abandonment. This represents an economic loss to various stakeholders [4]. Ipoh proliferates with many heritage sites as it was a tin mining center of the world and capital of Perak state, besides being

\footnotetext{
${ }^{a}$ Corresponding author : tsyeow@utar.edu.my
} 
the fourth largest city in Malaysia. Since the great fire of 1892, the original part of Old Ipoh city was rebuilt with brick buildings and clay roof tiles. The Chinatown part of Old Ipoh was concentrated on Leech Street [5]. However, Ipoh is experiencing a resurgent interest in heritage buildings and as part of a private led conservation effort; a case study on one of the century old heritage buildings along the intersection of Leech Street and Patrick Street was commissioned. The problem faced by many owners was a lack of technical based studies conducted to understand the types of physical defects present in such buildings and to conclude with appropriate solutions. The objective of this study is to identify the types and extent of defects as well as appraise the causes of these defects. The general significance of the study is that, by understanding the causes of defects through the life cycle of the building, a general guideline for heritage buildings maintenance can be framed for these buildings to be usable instead of being demolished for redevelopment. This is significant to provide reference to neighboring owners and those responsible for the conservation of heritage buildings with similar conditions to identify and prioritize critical defects in relation to the building life span to determine its condition.

\section{Literature Review}

The awareness to conserve Ipoh's heritage is increasing due to its rich mix of colonial era heritage buildings comparable with the straits settlements of Penang, Melaka and Singapore [5]. Old Ipoh town is currently experiencing a resurgence in interest due to the influx of outstation tourist as Perak is targeting to attract 5 million tourist in 2015 [6] due to its unique 'sense of place'. The preservation of the colonial era buildings were mainly due to the Rent Control Act that discouraged the redevelopment of the buildings from 1966 until its repeal in 1997 [7]. While the city council has guidelines on the conservation of these buildings, many building owners have minimal understanding of maintaining the authenticity of the building fabric and practically demolished the entire building except the front façade wall. The lack of specialized training and knowledgeable consultants and contractors probably contributed to the 'demolition approach' as they are more familiar with conventional work methods. However, the definition of heritage building is to retain its authentic character as evidence to a site's history and the minimal intervention approach is desired [4].

However, due to the inability of building owners to extensively repair a building while it is in use, as this would disrupt business operations, many such heritage buildings' ground floor would be functional while the first floor would be left abandoned once it was deemed unsafe to use. Old Ipoh mainly suffers from poor building conditions, high vacancy rate and low building utilization, as well accessibility. This depresses the rental rates, property prices and the variance may depend on different streets $[5,7]$. This raises the question of finding equilibrium between maintaining the authenticity of the materials and introducing new renovations in order to allow the continual use of the building as a building left vacant would invite much more problems. Generally, local heritage conservation lacks a holistic heritage maintenance planning [8].

In Malaysia, the thrust of heritage conservation of many of the nation's landmark buildings were undertaken by the public sector. However, the funds are limited for preventive measures to maintain all relevant buildings [9] as well as the lack of public awareness of internationally recognized guidelines such as the Burra Charter [10]. The public is now starting to be aware of the value of heritage buildings as a limited resource that forms part of the urban scenery as well as a tourism landmark and attraction [11]. This is where the private owners come in but they require the right guidance and approach to their property conservation independent of the oversight of the National Heritage Department [10]. The introduction of the National Heritage Act 2005 is a step in the right direction though it remains to be seen if building owners perceive it to be so. The potential is the private owners unlocking their financial investment in a manner that is sustainable and relieves the dependency of public funding. This requires an understanding of how the building fabric that is well conserved can impart its value in attracting businesses and customers and to reinvigorate the urban life. In Malaysia the model closely resembles the BCO (Build-Conserve-Operate) model [12]. However, most conservation management lacks the skill to interrogate the building's history due to 
the lack of archival materials. Most of the heritage conservation literature focus on the organizational management, programmatic and awareness approach but the technical application and building survey approach is lacking [13]. Therefore, this study is an initial investigation towards closing this gap.

\section{Research Method}

The study includes desktop sourcing of literature and interview with the neighboring shop owners who are in their $80 \mathrm{~s}$. The research method for the study includes a building survey approach: (a) taking dimensional scaled photographs of all building elevations, (b) to record building dimensions, (c) observation survey of ground level condition and estimate the extent of settlement, (d) dilapidation survey by visual observation, (e) determine building elements that have been renovated, and (f) observation of site context that may attribute to building condition. The case study process also requires an understanding of, (i) age of the building, (ii) the construction of historical buildings and the materials used, (iii) interpretation of the architectural style, (iv) historical record on the urban development, (v) introduction of modern utilities, (vi) history of defects appearing, and (vii) history of its functional use. This building survey study will serve as a guideline to manage the building maintenance for modern use.

\section{Findings and Discussion}

The building studied (Figure 1) is at the intersection of Patrick and Leech Street which faces the Kinta Height apartment block (Figure 2) that used to be the town market before it was relocated. The building is classifiable as Edwardian architecture as it was constructed between 1900 and 1910 .

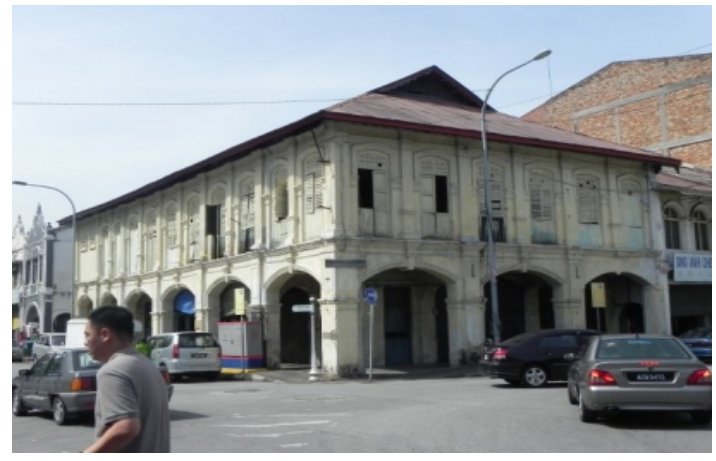

Figure 1. Case study building at Patrick Street.

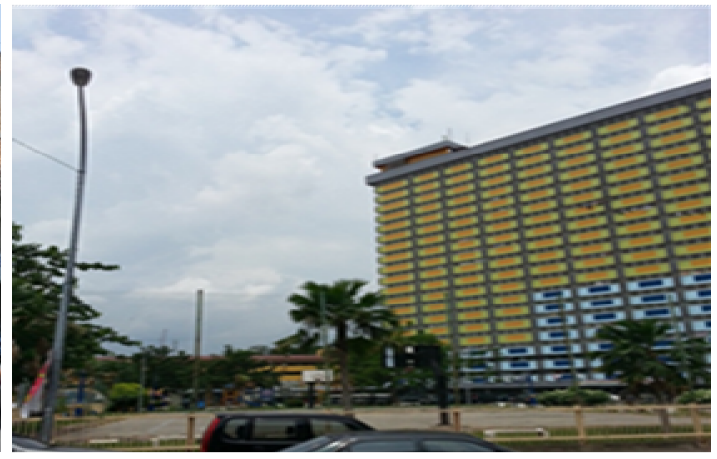

Figure 2. Kinta Heights apartment.

However, the original owner of the building as well as its original function could not be verified from historical records. From the interview, the building was used as a furniture shop before being converted to a school and later for retail of cooking wares with the first floor being used as store for about 40 years until 2014 where it was vacated. It was a period where plumbing technology was introduced but before connected sewer was established as the architecture utilized the 'bucket outhouse' system. Its original function was most probably designed for warehousing due to its internal riveted structural steel system, span and height as well as rear courtyard which is a different typology from the conventional shop houses. Table 1 shows the estimated period of major failures experienced by the building. The clay roofing was possibly replaced in the 1970s with asbestos roofing sheets. Building settlement were reported during the 1980s when the internal plumbing had to be replaced and the construction of Kinta Heights began. The building also has systemic cracks on its arches and ground floor slabs which had a 'saucer' shaped settlement and which is part of a larger eccentric settlement that most likely occurred during the construction of the 20 storey Kinta Heights. The 
building cracks are dormant but the overall crack pattern on the wall, edges of openings and the floor seem to indicate a horizontal soil movement occurring on the façade side facing Kinta Heights. Other major defects include the failure of $1^{\text {st }}$ floor timber balcony due to exposure to moisture and subsequent decay. The floor slab in the corridor has sunken between $75-80 \mathrm{~mm}$ (Figure 3 ) on the exterior and interior (Figure 4) of the building and this leads to a visible 'bow' of the building façade (Figure 5).

Table 1. Estimated period of element failure.

\begin{tabular}{|l|l|}
\hline $1903-1970$ & $\begin{array}{l}\text { Likely failure of terracotta barrel roof tiles, replaced with asbestos roof. The ground } \\
\text { floor fenestration renovated to folding door for commercial use. }\end{array}$ \\
\hline $1903-1980$ & $\begin{array}{l}\text { Likely failure of plumbing with leaks causing floor settlement. Replaced with } \\
\text { exposed piping. }\end{array}$ \\
\hline $1982-2014$ & $\begin{array}{l}\text { Likely crack defects start on walls due to settlement from the construction of the } \\
\text { adjacent Kinta Heights apartment block. Excessive loading and rain water ingress } \\
\text { contributed to decay of timber elements. }\end{array}$ \\
\hline
\end{tabular}

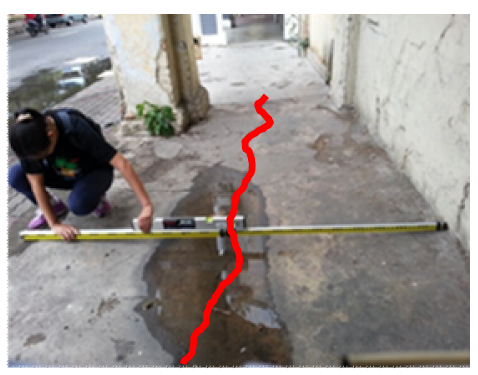

Figure 3. Settlement and water ponding

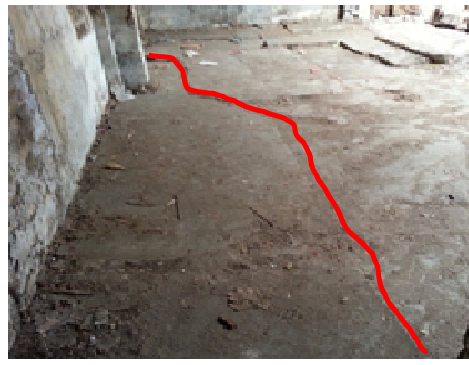

Figure 4. Interior floor crack.

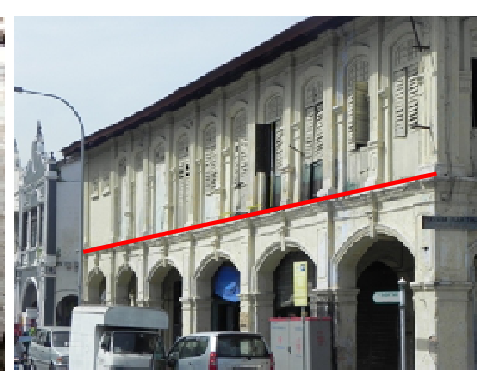

Figure 5. Façade bowing effect.

The areas with most settlement also coincide with the ingress of the plumbing pipe from the public main into the building. This pipe has since been replaced with and aboveground piping route, indicating that the previous pipe had leaked and this can cause soil erosion. The building's adjacent location to Sungai Kinta $(150 \mathrm{~m})$ may also contribute to the issue due to the fluctuation of water table levels during monsoon seasons which leads to annual flash flood. The primary concern is to ensure that the foundation is stabilized and further settlements are prevented and any causes of soil erosion are addressed. The crack patterns found on the arches and piers are part of the pattern of building envelope stress that forms, especially on a brick load bearing construction that does not cater to tensile stresses due to eccentric settlement. Other defects relate to moisture ingress through rising damp (failure of water barrier) and falling damp (failure of roof drainage). The building is deemed in good condition as most of the the lime plaster is not delaminating, nor the majority of the timber structure decaying or attacked by termites, indicating overall water tightness for the preservation of the building elements as well as effective ventilated drying of moisture.

\subsection{Proposed solutions}

Soil samples of the site are to be taken to determine the suitable of using cement grouting for foundation remediation. The benefits of this method are to avoid the need for excavation, cement the non-cohesive soil particles to prevent erosion and to improve the bearing capacity of the soil as well as to seal the adjacent public drain from future leaks. To further ensure that future problems are avoided, all plumbing pipes should be installed above ground and visible for maintenance. As the building is to retain its structural integrity, it is recommended that minimal destruction of its original envelope be permitted as it acts as a complete load bearing system. Instead, it requires future spatial needs to be adapted to its layout and this requires that the floor system must be upgraded and 
reinforced for modern fire compartmentalization standards and loadings. The introduction of new walls on the first floor is to be avoided unless they are lightweight partitions. Of concern are the balcony concrete slabs exposed to rain. A major failure for these floor systems over a century is that the timber battens that support the clay tiles and concrete topping above will sag over time due to water induced decay. This is a result of water seeping through the cracked concrete topping slab. Overtime, the previous owner abandons any repairs and the moisture seeps to the timber joists which in turn rots, loses strength and further sags, pulling at the adjacent brick walls, causing cracks. In such cases, the retention or demolition of such slabs to be replaced with reinforced concrete slabs must be considered in the context of future loading, water tightness and the necessity of historical authenticity.

At the ground floor of the building party wall, rising damp was detected along the entirety of the envelope. A chemical injection method is recommended for sealing off the ground water rising through capillary action. An alternative method is to allow for the rising damp to naturally ventilate and dry up to the average height is $4^{\prime}(1200 \mathrm{~mm})$. Any repairs to the plaster and paint are to use compatible technologies such as lime plaster and lime paint to ensure the 'breathability' of the finishes. As the original buildings do not consider the integrated design of plumbing and drainage, it is recommended that all future supply of water and drainage be kept to the rear perimeter of the building to avoid introducing any moisture to the interior. All piping ingress and egress to utilize existing openings to avoid damage to existing strip foundation. The final source of damp is the zinc roof gutter laid parallel to the party wall which had, over a century, rusted with rainwater seeping to the interior, causing a portion of the first floor and ceiling timber to rot over time. The roof is currently using asbestos roofing sheets as the roof was replaced in the early 1970s and poses a health hazard. It is recommended to be replaced with clay roof tiles that has good insulation properties and allows the roof system to ventilate while retaining the originality of the architecture.

\section{Conclusion and Recommendation}

This study has revealed the nature and extent of building defects which have profound implications on its choice of maintenance solutions. In order to reduce the cost of maintenance, other buildings of a similar nature must consider these guidelines: (a) the foundation and structural issues needs to be addressed sensitively by remediation and reinforcements methods (b) the maintenance and upkeep of the main roof system and especially the roof gutter, sealing off any exposed balcony against further infiltration of rainwater by introducing a layer of fenestration, (c) the compatibility of modern construction technologies with the existing building, (d) avoid covering up by ceilings or overcladding which will prevent visual monitoring especially on the connecting joints of different building components, (e) prevent embedded plumbing and electrical utility, (f) maintenance of drainage system, (g) prevent major hacking of load bearing sections which results in stressing the building envelope, (h) for newly introduced structures to avoid point loading design but to spread the load over a larger area and (i) upgrading of the 1st floor timber floor as well as the design of the staircase suitable for modern fire prevention and escape requirements. A suitable policy by the fire department is required to allow for heritage buildings to retain their authenticity while mitigating fire risk.

\section{References}

[1] Y. Ahmad, The scope and definitions of heritage: from tangible to intangible, International J. of Heritage Studies, 12(3), 292-300, (2006).

[2] C.L. Cartier, Conserving the built environment and generating heritage tourism in Peninsular Malaysia, Tourism Recreation Research, 21(1), 45-53, (1996).

[3] W.H Wan Ismail and S. Shamsuddin, The old shophouses as part of Malaysian urban heritage: The current dilemma, Proc. of the 8th International Conference of the Asian Planning Schools Association, (2005).

[4] S.N. Harun, Heritage building conservation in Malaysia: experiences and challenges, Procedia Engineering, 20, 41-53, (2011). 
[5] W.W. Lim, Hew-David, Y.K. Tong-Gerald and G.G. Goh, Revitalisation of the old township of Ipoh, Malaysia, J. of Place Management and Development, 7(1), 57-73, (2014).

[6] Ipohecho, Perak Targets Five Million Tourists, (2015), <available at: http://www.ipohecho.com.my/v3/article/2015/02/01/perak-targets-five-million-tourists >

[7] S. Atumi, The repeal of rent control in Malaysia, Cornell Real Estate Review, 2, 29-38, (2003).

[8] A.F. Mohd-Isa, Z. Zainal-Abidin and A.E. Hashim, Built heritage maintenance: A Malaysian perspective, Procedia Engineering, 20, 213-221, (2011).

[9] R. Talib, A.G. Ahmad, N. Zakaria and M.Z. Sulieman, Assessment of factors affecting building maintenance and defects of public buildings in Penang, Malaysia, Architectural Research, 4(2), 48-53, (2014).

[10]R. Abdul Rashid and A.G. Ahmad, The implementation of maintenance works for historical buildings- a review of the current scenario, Procedia Engineering, 20, 415-424, (2011).

[11]N.F. Nik-Azhari and E.Mohamed, Public perception: Heritage building conservation in Kuala Lumpur, Procedia Social and Behavorial Sciences, 50, 271-279, (2012).

[12]S. Macdonald, Leveraging heritage: Public-private and third sector partnership for the conservation of the historic urban environment, ICOMOS Conference, Paris (2011).

[13]R. Abdul Rashid and A.G. Ahmad, Overview of maintenance approaches of historical buildings in Kuala Lumpur- a current practice, Procedia Engineering, 20, 425-434, (2011). 